\title{
ERRATUM
}

\section{Carriage and Fecal Counts of CTX-M-Producing Escherichia coli in Pigs: a Longitudinal Study}

\section{Katrine Hartung Hansen, Peter Damborg, Margit Andreasen, Søren Saxmose Nielsen, Luca Guardabassi}

University of Copenhagen, Faculty of Health and Medical Sciences, Department of Veterinary Disease Biology, Frederiksberg, Denmark; Danish Agriculture and Food Council, Pig Research Centre, Copenhagen, Denmark; University of Copenhagen, Faculty of Health and Medical Sciences, Department of Large Animal Sciences, Frederiksberg, Denmark

Volume 79, no. 3, p. 794-798, 2013. Page 794: The article title should read as shown above.

Page 794, column 1, paragraph 1, lines 5 and 6: "Cefotaxime M (CTX-M) enzymes" should read "CTX-M enzymes." 